\title{
Language Strategies in Legal Reasoning of Judgments: an Engagement-Adaptation Model
}

\author{
Wenxiu Song \\ School of Foreign Languages, Southwest University of Political Science and Law \\ 401120, Chongqing, China \\ E-mail: viviansong1@163.com
}

Received: October 24, 2019 Accepted: January 20, 2020 Published: February 3, 2020

doi:10.5296/ijele.v8i1.16384 URL: https://doi.org/10.5296/ijele.v8i1.16384

\begin{abstract}
Legal reasoning, as the core of the judgment, has always been the focus of legal community. While in fact, the reasoning of judgment is not only related to knowledge of jurisprudence but also associates closely with the use of language strategies and thus deserves the attention of linguistic scholars. This study attempts to explore the language strategies underlying the legal reasoning of judgment based on engagement system of appraisal theory and adaptation theory. Through analyzing the legal reasoning of ten American judgments, it is found that substantial engagement resources are employed in the reasoning, among which Attribute occurs most frequently, followed by Deny, Entertain, Counter, Endorse, and Pronounce is the least favored resource in the legal reasoning of judgments, which is the result of the adaptation to the social role of the judges, the relationship between power and equality in court, as well as the expected psychology of the audience of the judgments.
\end{abstract}

Keywords: legal reasoning, judgment, heteroglossic engagement, appraisal theory, adaptation theory 


\section{Introduction}

Legal reasoning of judgment refers to the justification of legal decisions made by judges (Paunio \& Hovinheimo, 2010). As the core of judicial adjudication, the reasoning is of great significance in that it forms effective restrictions on judges' discretion and guarantees the fairness of the judgments to a certain extent. Besides, the rationalization of the sentence helps to enhance the acceptability of the judgment. In short, improving legal reasoning can, to an extent, guarantee the quality of judges, establish legal authority and achieve judicial justice.

Legal reasoning relates not only to the knowledge of jurisprudence, but also to the use of language. The previous studies on legal reasoning are conducted primarily from the perspective of structuralist (Hermann, 1975), rhetoric (Manzin, 2012), semantics (Brewer \& Scott, 1996; Khachatryan, 2014; Ronald \& Stamper, 1991; Verenich, 2012), pragmatics (Brewer \& Scott, 1996; Feteris \& Eveline, 2016) and semiotics (Verenich, 2012), all of which push forward the researches on legal reasoning and facilitate our understanding of this particular genre. However, the heteroglossia of the reasoning of judgments is ignored in previous studies. As a matter of fact, legal reasoning is a kind of interaction between judges and their audience in which judges aim to deliver their opinions about the current case to the audience, and strive to persuade the audience to share the same viewpoints or position. It can be clearly seen in the reasoning of judgments that a variety of heteroglossic engagement resources are employed. According to Verschueren (1999: 55-57), using language is a process of continuous making of linguistic choices to adapt to the social, mental and physical world, and judges' reasoning with engagement resources in no exception. That is to say, starting from engagement system of appraisal theory, this study analyzes the language strategies in legal reasoning, namely, the employment of heteroglossic engagement resources, and explores the underlying contextual adaptation mechanism.

\section{Analytical Model}

\subsection{Engagement System}

As a breakthrough of the studies on interpersonal meaning within Systemic Functional Linguistics, appraisal theory is a semantic system consisting of three subsystems, namely, attitude system dealing with human's feelings, engagement system concerning with different voices in discourse and graduation system regulating the degree of the engagement of attitude (Martin \& Rose, 2003; Martin \&White, 2005).

Inspired by Bakhtin's and Voloshinov's dialogism and heteroglossia, Martin and White (2005) propose that engagement refers to language resources used to indicate the source of voices of speaker/ writer or text, or employed for speaker/ writer to negotiate and adjust the responsibilities for what is said/ written. Martin and White (2005) hold that the speaker/ writer always reveals the influence of what has been said/ written to anticipate the responses of actual or potential readers/ hearers. Besides, they divide the engagement theory into monogloss and heterogloss. The former refers to the bare assertion, in which writer/ speaker is responsible for all evaluation with only one source of voice rather than engage any dialogic alternative. By contrast, heterogloss invokes or allows for alternative viewpoints and the 
responsibilities are attached to different voices. This study lays stress on the aspect of heteroglossia to explore how judges interact with the audience, specifically, how they pass on their opinions, establish alignment with the audience in order to convince them of the judgments. Heterogloss can be divided into subcategories according to their respective functions in discourse, that is, dialogic expansion and dialogic contraction.

Dialogic expansion refers to the resources which expand the dialogic space for different voices and positions, and it is achieved by Entertain and Attribute resources. Entertain means that the position of the authorial voice is but one of many possibilities and thus allowing dialogic space for those possible positions (Martin \& White, 2005: 104). Modal auxiliary verbs, modal attributes and inferential clauses are typical realization of Entertain. Attribute refers to those resources which dissociate the proposition from the text's internal authorial voice by attributing it to some external sources, typically realized by directly and indirectly reported speech and thought (Martin \& White, 2005: 111). Dialogic contraction is composed of Disclaim and Proclaim. The former includes Deny and Counter, while the latter consists of Concur, Pronounce and Endorse. Martin and White (2005) state that Deny is a kind of resource used for introducing the alternative positive position into the dialogue, then admitting and finally rejecting it. Counter is another form of denial involving formulations which represent the current proposition as replacing or supplanting, and thereby countering a proposition that would have been expected in its place (Martin \& White, 2005: 120). In the category of Proclaim, Concur refers to the expressions which explicitly announce the addresser as agreeing with some projected dialogic partner or show the same knowledge and background (Martin \& White, 2005: 122). Pronounce concerns with formulations that involve authorial emphases or explicit authorial interventions or interpolations (Martin \& White, 2005: 127). Endorse refers to those locutions by which propositions sourced to out-of-text sources are construed by the authorial voice as correct, valid, undeniable or otherwise maximally warrantable (Martin \& White, 2005: 126). Heteroglossic engagement system can be illustrated in Figure 1.

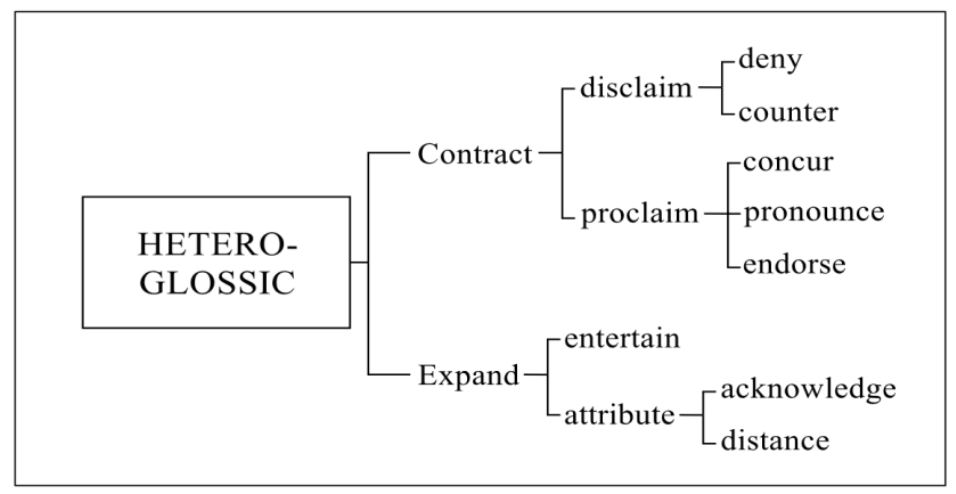

Figure 1. Heteroglossic engagement system 


\subsection{Adaptation Theory}

Adaptation was systematically presented by Verschueren in Pragmatics as a Theory of Linguistic Adaptation in 1987, viewing the use of language as a continuous course of making linguistic choices. This theory examines the process of language adaptation from four dimensions, namely, contextual correlates, structural objects, dynamic process and degree of consciousness salience (Verschueren, 2000). The contextual correlates of adaptability involve all the contextual ingredients, including linguistic context and communicative context. This study mainly focuses on the latter which is comprised of language users, mental world, social world and physical world. The language users contain the utterer and interpreter who play roles in producing and interpreting an utterance respectively. During the process of communication, mental factors of both the utterer and interpreter are taken into account and get activated. The mental world in the context primarily covers the aspects of belief, personality and intentions of language users (Verschueren, 1999). It should be noted that linguistic choices made are not only adapted to the mental world of the utterer, but also to that of the interpreter based on the assessment of the utterer. What's more, language use in a specific society is intertwined with some social factors including the social background of a specific time, the social status of language users and the norms and values of a society. In addition, the physical world refers to those material conditions of language users, to be specific, the nature and the physical state. Physical surroundings of language use chiefly refer to the temporal and spatial relations while the physical state of language users mainly includes their posture, gaze, gesture and so forth.

The legal reasoning of judgment is a dynamic process in which judges choose language, specifically, heteroglossic engagement resources, to adapt to specific communicative context.

\subsection{Engagement-Adaptation Model}

Appraisal theory and contextual adaptation of Verschueren are integrated to establish an engagement-adaptation analytical model as Figure 2, interpreting the reasoning process of judgments as a dynamic process in which judges make language choices out of the adaptation to the context of communication. To be specific, this study focuses on the choice of engagement resources made by American judges in the reasoning of judgments, primarily including Deny, Counter, Pronounce, Endorse, Entertain and Attribute. Contextual adaptation mainly includes three aspects, namely, social world, mental world and factors concerning the audience of the judgments. Specifically, the social world that judges adapt to includes the social role of judges and the relationship between power and equality in the trial. The mental world of judges mainly refers to the belief and specific intentions of judges, while factors concerning the audiences chiefly refers to their expectation.

According to the above analytical model which can be illustrated as Figure 2 below, this study first analyzes statistically and describes the heteroglossic engagement resources selected in the reasoning of American judgments and then discusses the mechanism and motivation under such language choices from the perspective of contextual adaptation. 


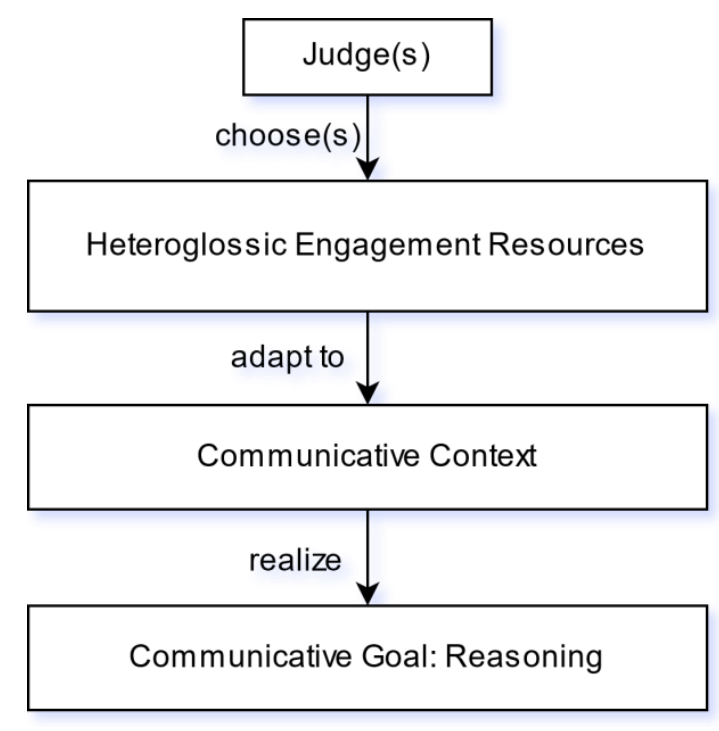

Figure 2. Engagement-adaptation model in reasoning of judgments

\section{Research Methodology}

\subsection{Research Questions}

The study will answer the following questions:

(1) How are heteroglossic engagement resources distributed in American judgments?

(2) What are the effects of those engagement resources?

(3) How judges employ those engagement resources to adapt to the communicative context?

\subsection{Research Procedures}

Firstly, the legal reasoning of ten pieces of judgements are selected at random on https://lp.findlaw.com and made into a corpus. Secondly, UAM Corpus Tool 3.3 with the coding scheme of heteroglossic engagement system is used to proceed with manual annotation on the engagement resources in the corpus and count the number as well as frequency. Thirdly, the statistical results obtained are presented. Finally, the author figures out the characteristics of these resources employed and unravels how judges employ them to adapt to the communicative context to realize their communicative goals.

\subsection{Research Approaches}

Qualitative and quantitative research methods are adopted to conduct the study. The quantitative approach is used to identify the frequencies and distributions of different heteroglossic engagement resources in the selected corpus. It is responsible for answering the first question: (1) How are engagement resources distributed in American judgments? Besides, the qualitative method further analyzes how judges employ different resources to adapt to the communicative context to achieve their communicative goals. In other words, the qualitative approach in this study is used to describe and interpret some specific instances of engagement resources, dealing with the second and third question: what are the effects of 
those engagement resources? (3) How judges employ heteroglossic engagement resources to adapt to the communicative context?

\section{Result and Discussion}

\subsection{Heteroglossic Engagement Resources in American Judgments}

The reasoning of the ten judgments is processed by UAM Corpus Tool 3.3. It calculates the frequency of heteroglossic engagement resources of judgments and brings forth the results as follows.

Table 1. Heteroglossic engagement resources in the reasoning of American judgments

\begin{tabular}{llc}
\hline Feature & Number $(\mathbf{N}=737)$ & Percent (Global) \\
\hline Deny & 148 & $20.08 \%$ \\
Counter & 102 & $13.84 \%$ \\
Pronounce & 35 & $4.75 \%$ \\
Endorse & 74 & $10.04 \%$ \\
Entertain & 147 & $19.95 \%$ \\
Attribute & 231 & $31.34 \%$ \\
\hline Total & 737 & $100 \%$ \\
\hline
\end{tabular}

Table 1 shows that in the reasoning of judgments, American judges favor dialogic expansion than contraction with 378 instances versus 359 instances, which accounts for $51.28 \%$ versus $48.71 \%$ respectively. The most frequently-used heteroglossic engagement resource is Attribute, with 231 instances, taking 31.34\%, followed by Deny (148 instances, 20.08\%), Entertain (147 instances, 19.95\%), Counter (102 instances, 13.84\%), Endorse (74 instances, $10.04 \%$ ), and the least-favored resource in the judgments is Pronounce (35 instances, $4.75 \%$ ).

As part of Disclaim, Deny refers to the rejection or challenge towards a certain viewpoint. More than a negative expression, Deny is a resource for introducing the positive position into the dialogue and then denying it. Realized by not, no, nothing, none and words with negative prefix, etc., it attempts to narrow down the space for dialogue and limit the possibility of existence of the other alternative voices.

(1) The court did not (Deny) specify whether the awards were separate awards for which Appellants were separately liable, or if Appellants were jointly and severally liable for the full amount.

By virtue of did not, the judges overrule the previous judgments and project their position as rejecting the litigation or previous judgments. As a result, the judges contract the dialogic space to explicitly express their own views and suppress the alternatives to establish solidarity with the audience with the same stance and disalign from those holding the opposite views, without losing their authority in the process of communication.

Another subtype of Disclaim is Counter, which typically draws the proposition of counter-expectancy for readers. The merits of Counter resources lie in proposing the 
viewpoints suspended by writers, admitting its rationality, narrowing the distance with the readers, and muting the potential opposite voices from readers, which highlight their own views. The values of propositions are highlighted through the replacement and contrast of propositions so that the speaker and audience can enter the same dialogical scope, which conduces to the establishment of alliances with the audience holding the opposite opinion. Counter is typically represented by although, yet, but, however, or comment adjuncts/ adverbials such as amazingly, surprisingly, suddenly and so on.

(2) Although (Counter) we agree that $\S 408$ (c) represents a liberalization of the copyright laws, it does not define the requirements for a valid copyright registration.

In example (2), the judges construe the audience anticipate that the judges agree that $\S 408$ (c) represents a liberalization of the copyright laws and employ although to admit alternatives held by the audience firstly and then the audience are drawn to the opposite scope of dialogue by logical deduction. Though the dialogic space is narrowing, the judges allow the existence of different voices. In this way, judges make their utterances more convincing and realize their purpose of persuading the audience and aligning with them.

Pronounce serves as an effective strategy used to suppress the alternative voices by declaring the speaker's/ writer's position. It displays the explicit engagement of the writer's/ speaker's view into the text, highlighting the opinions of the writer/ speaker. It is achieved primarily by I/we contend, the facts of the matter are..., indeed and so on. By employing Pronounce, the writer/ speaker assumes the responsibility for their words and/ or strengthen the warrantability of the proposition.

(3) Indeed (Pronounce), we have allowed a good- faith belief in fair use to negate willfulness only if a defendant has taken reasonable steps to assure fair use before infringement, not as a "post-hoc rationalization connected to skirt liability."

With the help of indeed, the reliability of the proposition is improved against potential doubts. Besides, little space is left for other alternatives in the current dialogical scope, disaligning the judges from the opposite side.

Endorse refers to those formulations by which proposition sourced to out-of-text source are construed as correct, valid, undeniable or otherwise maximally warrantable (Martin \& White, 2005 : 125). It is represented by certain verbs such as demonstrates, shows, proves, point out and so forth.

(4) Plaintiffs asserting contributory trademark infringement claims must (Endorse) prove that defendants provided their services with actual or constructive knowledge that the users of their services were engaging in trademark infringement. See Inwood Labs., 456 U. S. at 854; Perfect 10. Inc. v. Visa Int'1 Serv. Ass'n. 494 F. 3d788, 807 ( $9^{\text {th }}$ Cir. 2007) (Endorse).

(5) Testimony by David Spradley, a co-creator of "Atomic Dog", also demonstrated (Endorse) that Clinton exercised some degree of creative control over the panting by instructing the performers to create a certain rhythm.

From all the above examples, it can be seen that judges not only align with those external 
voices while they use demonstrate and cite the precedent, but also implies that any position opposed to these external voices is incorrect or invalid. Actually, judges are using the external texts to support their stance. In judgments, judges tend to cite the precedent or use relevant evidence or the findings in the courtroom to support their arguments. Judges in example (4) and example (5) resort to relevant precedent and evidence to support their stance, making their arguments more objective and persuasive.

Entertain indicates that the speaker/ writer acknowledges that there are different viewpoints. By virtue of Entertain, the speaker/ writer adjusts the interpersonal distance and respects dialogical alternatives to hearers'/ writers' reliance on the text. It is represented by perhaps, may/might, could, must, etc., via modal adjuncts such as it's possible that..., it's likely that..., etc., via circumstances of the in my view type and via certain mental verb/ attribute projections such as I suspect that..., I think, believe, I'm convinced that, I doubt, it seems to $m e$, etc., or expository questions.

(6) One party might (Entertain) own the copyright in the words and musical arrangement of a song, and author party might (Entertain) own the copyright in a particular artist's recording of those words and musical notes.

In example (6), the judges employ the low- and medium-value modality might to make the propositions as controversial and express negotiability, allowing different voices from the audience.

Attribute deal with those formulations which dissociate the proposition from the text's internal authorial voice by attributing it so some external source, including Acknowledge and Distance. The former refers to those formulations which not overtly indicate that the authorial voice stands with respect to the proposition and recognizes that the external voice is one of many possibilities. It is typically realized by means of reporting verbs such as say, state, declare, report, announce, believe and think, or phrases such as according to, in one's view. Acknowledgment of external voices is necessitated in judgments for the sake of dealing with controversial issues, in the form of judges' arguing with them or using them to support their stance. In the judgments, the main sources of Acknowledge are participants.

(7) According to Louis Vuitton (Attribute, Acknowledge), the customers who directly infringed the trademarks and copyrights were based in China.

In the example above, by virtue of assigning the authorial responsibility to the external voice, judges appear unimplicated in the value positions in the attributed materials, which avoid conflict with the opposed audience. Or it can be said that the judges are trying to establish alignment with them.

Distance refers to locutions that explicitly distance the authorial voice from the attributed material. It is usually realized with the help of reporting verb such as claim, so-called or via scare quotes, which has specific functions such as distancing oneself from the outside voice, using its authority to support one's position, showing a usage to new or tentative, or introducing a new word (Fairclough, 1992: 119). 
(8) Appellants also contend that the jury instructions were erroneous because, in their view, "contribution to infringement must be intentional for liability to arise" (Attribute, Distance). We disagree.

With the help of scare quotes, the judges explicitly emphasize that the proposition is the assertion of the litigants, thus indicating the objectivity of the proposition, shirking responsibility for the credibility of the propositions and showing their disalignment. As a result, the judges decrease the interpersonal cost and invite more alternatives to take part in the negotiation. On the other hand, they align with those who take a stand against the attributed materials.

\subsection{Contextual Adaptation in American Judgments}

According to Verschueren (1999), language use is a process of constant choice making, and dynamic adaptation should be made in the process of using any language. Judges' employment of heteroglossic engagement resources in legal reasoning is no exception.

\subsubsection{Adapt to the Expected Psychology of the Audience of Judgments}

In the view of Verschueren (1999: 67-68), speaker is always trying to adapt to the psychological state of the audience assessed by the speaker when making language choice. Judges choose the heteroglossic engagement resources rationally out of the adaptation to the assessed psychological state of the audience of the judgments.

(9) As relevant here, the Copyright Act requires (Endorse)the Board to set "reasonable terms and rates" for royalty payments made under the $\S 115$ license when the parties to the license fail to do so.

(10) According to an expert musicologist (Endorse), the Bow Wow refrain "is one of the most memorable parts of the song" and is often licensed by itself.

(11) But, fragmented literal similarity has been applied by district courts in our circuit and, as noted above, by our sister circuits. See, e.g., Neal Publ'ns v. F \& W Publ'ns, Inc. 307 F. Supp. 2d. 298, 931 (N. D. Ohio 2004); Tree Publ'n v. Warner Bros. Records, 785 F. Supp. 1272, 1275 (M. D. Tenn. 1991) (Endorse).

From the above examples, it can be clearly seen that American judges favor Endorse resources in the reasoning of judgments, specifically, cite related laws, authoritative evidence or precedents to support their legal reasoning. Judges are particularly fastidious when choosing language strategies and copiously quote authoritative works to manifest the rationale and objectivity of their reasoning. In this case, Endorse becomes the first-line strategy. In order to make their decisions more acceptable to the audience, the judges will resort to Attribute resources to remove the arbitrariness of their opinions and attempt to guarantee the objectivity and rationality of the reasoning. In a word, the judges adapt to the psychological expectations of the audience and strive to make a reasonable and objective judgment by choosing such resources as Endorse and Attribute. 


\subsubsection{Adapt to the Social Role of Judges}

In the judicial practice of the US, the primary duty of a judge is to decide cases and make judgments, which is showcased in the judge's analysis of the previous judgments to lay a foundation for his decisions. There are many differences in the way judges decide cases in the US. For instance, in the court of first instance, cases are typically decided by a judge, while those in the appellate court are processed by the collective efforts of several judges (Baum, 1994: 38-19). As the corpus of this study is mainly comprised of the decisions on appeal, this study focuses on the social role of the judges of appellate instance. Due to the influence of the case law system, the judges of appellate instance in the US usually act as "lawmakers" while adjudicating cases in that the judgments they make may be established as legal rules and have an impact on the subsequent cases and even some social activities.

(12) Appellants also contend (Attribute) that the jury instructions were erroneous because, in their view, "contribution to infringement must be intentional for liability to arise." (Attribute) We disagree (Deny).

In example (12), engaging strategies Attribute and Deny are employed to classify the opinions of the judges. Realized by argue and contend, Attribute is used to represent judges' distance with the defendant's views, so as to adapt to the social role of the judges as adjudicators of the case. Furthermore, rather than directly announce the decisions, the judges choose Deny resources to imply the objectivity of the judgments, facilitating the adaptation to their social role as neutral arbiters.

\subsubsection{Adapt to Relationship between Power and Equality in Court}

The relationship between power and equality, which are unified and complementary to each other, is embodied in the trial procedure of the US. In order to adapt to the balance between them, American judges choose a variety of engagement resources to achieve reasoning and demonstrate power as well as equality in the judgments to some extent, which in turn highlights the objectivity and rationality of the process of reasoning.

Appellants also contend (Attribute) that the jury instructions were erroneous because, in their view, "contribution to infringement must be intentional for liability to arise. (Attribute)" We disagree (Deny). Plaintiffs asserting contributory trademark infringement claims must (Entertain) prove that defendants provided their services with actual or constructive knowledge that the users of their services were engaging in trademark infringement. See Inwood Labs., 456 U. S. at 854; Perfect 10. Inc. v. Visa Int'1 Serv. Ass'n. 494 F. 3d788, 807 $\left(9^{\text {th }}\right.$ Cir. 2007) (Endorse). An express finding of intent is not (Deny) required.

Selected from the case Louis Vuitton Malletier v. Akanoc Solutions Inc, the above examples are the reasoning for the grounds of appeal of the appellant "the jury instructions were erroneous". Four kinds of engagement resources are employed in the reasoning, among which Attribute and Deny are used most frequently. Moreover, adapting to different speakers/ writers, the judges choose different engaging strategies. Specifically, they employ Attribute when reporting or quoting the words of the appellants while adopting Endorse resources when citing precedents to support their opinions. Deny, Counter and Pronounce, as strategies 
of dialogic contraction, is primarily used to show the power of speaker/ writer; Entertain and Attribute, resources used for expanding dialogic space, are language embodiments of equal relationship, allowing room for other alternatives. Therefore, American judges often distribute these resources comprehensively in the reasoning of judgments to adapt to the relationship between power and equality, maintain the balance between them and enhance the reasonability of their judgments.

\section{Conclusion}

Based on the appraisal theory and adaptation theory, this study analyzes the employment of heteroglossic engagement resources in the reasoning of American judgments, and probes into the underlying contextual adaptation mechanism and motivation. It is found that a large number of heteroglossic engagement resources are employed in the reasoning of judgments, among which Attribute is used most frequently, followed by Deny, Entertain, Counter and Endorse, and Pronounce is the least-favored strategy, which is the result of the adaptation to the social role of the judges, the relationship between power and equality in the trial, and the psychological expectation of the audience of the judgments. It is hoped that this study can provide enlightenment for the improvement of the legal reasoning of judgments and guarantee judicial justice.

\section{References}

Baum, L. (1994). American Court (3rd ed.). Houghton: Houghton Mifflin Company.

Brewer, S. (1996). Exemplary reasoning: semantics, pragmatics, and the rational force of legal argument by analogy. Harvard Law Review, 109(5), 923-1028. https://doi.org/10.2307/1342258

Fairclough, N. (1992). Discourse and Social Change. Cambridge: Polity Press.

Feteris, E. T. (2016). Prototypical argumentative patterns in a legal context: The role of pragmatic argumentation in the justification of judicial decisions. Argumentation, 30(1), 61-79. https://doi.org/10.1007/s10503-015-9376-0

Hermann, D. (1975). A structuralist approach to legal reasoning. Southern California Law Review, 48, 1131-1194. https://doi.org/10.1093/oxfordhb/9780198794356.013.29

Khachatryan, R. Linguistic and Semantic Aspects of Causation in Legal Reasoning in Modern English. Armenian Folia Anglistika, 31-44.

Manzin, M. (2012). A rhetorical approach to legal reasoning. Exploring Argumentative Contexts, (4), 137.

Martin, J. R., \& White, P. R. R. (2005). The Language of Evaluation: Appraisal in English. New York: Palgrave Macmillan.

Martin, J. R., \& White, P. R. R. (2005). The Language of Evaluation. New York: Palgrave. 
Paunio, E., \& Lindroos-Hovinheimo, S. Taking language seriously: an analysis of linguistic reasoning and its implications in EU law. European Law Journal, 16(4), 395-416. https://doi.org/10.1111/j.1468-0386.2010.00515.x

Stamper, R. K. (1991). The role of semantics in legal expert systems and legal reasoning. Ratio Juris, 4(2), 219-244. https://doi.org/10.1111/j.1467-9337.1991.tb00094.x

Verenich, V. (2012). The semiotic model of legal reasoning. International Journal of Law, Language \& Discourse, (2), 25.

Verschueren, J. (1999). Understanding Pragmatics. London/ New York: Arnold.

Verschueren, J. (2000). Understanding Pragmatics. Beijing: Foreign Language, Teaching and Research Press.

\section{Copyright Disclaimer}

Copyright for this article is retained by the author(s), with first publication rights granted to the journal.

This is an open-access article distributed under the terms and conditions of the Creative Commons Attribution license (http://creativecommons.org/licenses/by/3.0/). 